\title{
Validated age and growth estimates for Carcharhinus obscurus in the northwestern Atlantic Ocean, with pre- and post management growth comparisons
}

\author{
Lisa J. Natanson • Brian J. Gervelis • Megan V. Winton • \\ Li Ling Hamady • Simon J. B. Gulak • John K. Carlson
}

Received: 9 April 2013 / Accepted: 23 September 2013 / Published online: 19 November 2013

(C) Springer Science+Business Media Dordrecht (outside the USA) 2013

\begin{abstract}
Age and growth estimates for the dusky shark, Carcharhinus obscurus, were derived from vertebral centra collected in the northwestern Atlantic Ocean. Sample collection spanned the years prior to and following the implementation of management measures (19632010). Growth was compared pre- and post- population depletion and pre- and post- management to investigate the possibility of density-mediated shifts in age and growth parameters over time. There was no evidence of difference between periods for either sex. Additionally, bomb radiocarbon dating was used to determine the periodicity of band pair formation. Results support the traditional interpretation of annual band pairs up to approximately 11 years of age. After this time, vertebral counts considerably underestimate true age. Maximum validated ages were estimated to be between 38 and 42 years of age (an increase of 15 to 19 years over the
\end{abstract}

L. J. Natanson $(\bowtie) \cdot$ B. J. Gervelis

USDOC/NOAA/NMFS,

28 Tarzwell Dr., Narragansett, RI 02882, USA

e-mail: Lisa.Natanson@noaa.gov

M. V. Winton

USDOC/NOAA/NMFS,

166 Water St., Woods Hole, MA 02543, USA

L. L. Hamady

Woods Hole Oceanographic Institution,

Marine Research Facility 235, MS\#50, Woods Hole, MA

02543, USA

S. J. B. Gulak · J. K. Carlson

USDOC/NOAA/NMFS,

3500 Delwood Beach Road, Panama City, FL 32408, USA band count estimates), confirming longevity to at least 42 years of age. Growth curves estimated using only validated data were compared to those generated using band pair counts. Logistic growth parameters derived from validated vertebral length-at-age data were $L_{\infty}=$ $261.5 \mathrm{~cm} \mathrm{FL}, L_{o}=85.5 \mathrm{~cm}, t_{o}=4.89$ year and $\mathrm{g}=$ 0.15 year $^{-1}$ for the sexes combined. Revised estimates of age at maturity were 17.4 years for males and 17.6 years for females.

Keywords Dusky shark - Age and growth . Elasmobranch . Vertebrae $\cdot$ Bomb radiocarbon .

Validation

\section{Introduction}

Density-dependent responses to population reduction in elasmobranchs are poorly understood (Walker 1998; Gedamke et al. 2005; Cortés 2007), although they potentially play an important role in a population's ability to sustain or recover from fishing mortality. Empirical data documenting such density-mediated shifts in age, growth and maturity in elasmobranchs are generally limited; to date, evidence of compensatory growth has been reported in two members of the United States (U.S.) coastal shark complex. Growth reportedly increased in both juvenile sandbar sharks, Carcharhinus plumbeus, in the northwest Atlantic (Sminkey and Musick 1995) and Atlantic sharpnose sharks, Rhizoprionodon terraenovae, in the Gulf of Mexico (GOM; Carlson and Baremore 2003) following fishery-induced decreases in abundance. 
The dusky shark is a common coastal pelagic carcharhinid that is widely distributed in the world's oceans (Compagno 1984) and considered a single, genetic stock in the northwest Atlantic and GOM (Benavides et al. 2011). It is considered one of the most vulnerable species to overexploitation due to its combination of slow growth, late age at maturity (19-21 years), small litter sizes (3-12 embryos), and tri-annual gestation (Natanson et al. 1995; Romine et al. 2009).

Along the eastern coast of the U.S., directed fisheries for large coastal sharks emerged in the 1970s and increased through the 1980s due to greater demand for shark products worldwide (NMFS 2011). Management was initiated for Atlantic and GOM sharks, including the dusky shark, in the Fishery Management Plan developed by National Marine Fisheries Service (NMFS) in 1993. Multiple stock assessments depict a decline in the northwest Atlantic and GOM dusky shark populations to as little as $15-20 \%$ of their mid1970s abundance by the late 1990s (Cortés et al. 2006; NMFS 2011). In response to such severe declines, dusky sharks were listed as a prohibited species in 2000 in both the northwest Atlantic and GOM (NMFS 1999). Additionally, a time/area closure was implemented off North Carolina in 2005 to help reduce the impact of fishing on an area where juvenile dusky sharks are known to congregate (NMFS 2003). Given the decline in abundance, dusky sharks in the northwest Atlantic may have experienced lower levels of intra-specific competition in the years following the peak of fishing activity, which may translate to changes in life history parameters over time.

Age and growth estimates were reported for dusky sharks in the northwest Atlantic during the period prior to management (Natanson et al. 1995). The observed maximum age for the species was 33 years; age at maturity for males and females was estimated at 19 and 21 years, respectively. While band pair deposition in the previous study was assumed to be annual, age estimates were not validated. Annual deposition of countable growth increments cannot be assumed through the complete lifespan because band pair deposition may stop or become irresolvable when somatic growth slows or ceases (Kalish and Johnston 2001; Francis et al. 2007; Andrews et al. 2011; Hamady et al., Bomb Radiocarbon Confirmation of Extreme Longevity in White Sharks (in review)). Such species can reach ages far older than that estimated by band pairs in vertebral centra. In recent studies where annual deposition has been validated in smaller specimens, longevities based on band pair counts have proven to be underestimates when validation is achieved over the entire size range (Andrews et al. 2011; Hamady et al., Bomb Radiocarbon Confirmation of Extreme Longevity in White Sharks (in review)).

The objectives of this study were to update age and growth parameter estimates for the dusky shark in the northwest Atlantic. Specifically, we investigate if any changes in growth have occurred over time due to potential density dependent effects. We also validate growth band deposition using bomb radiocarbon dating techniques.

\section{Materials and methods}

Vertebral preparation and interpretation

Vertebrae were obtained from dusky sharks caught using longline, trawl, and rod and reel gear on research cruises, commercial and recreational fishing vessels, and at sport fishing tournaments along the northeast coast of the U.S. between Florida and Cape Cod, Massachusetts, from 1963 to 2010. When possible, the $15^{\text {th }}$ through $20^{\text {th }}$ vertebrae were excised. If such precision was not possible, this section of backbone was approximated as the branchial region adjacent to the fifth gill arch. Vertebrae were cleaned and stored frozen or preserved in either $10 \%$ buffered formalin or $70 \%$ ethanol.

Only samples that had measured fork length (FL-tip of the snout to the fork in the tail, over the body) or total length (TL-tip of the snout to a point on the horizontal axis intersecting a perpendicular line extending downward from the tip of the upper caudal lobe to form a right angle) were used. All lengths reported are in FL $(\mathrm{cm})$ unless otherwise noted. For specimens with only a recorded TL, FL was estimated using the regression equation reported by Kohler et al. (1995):

$\mathrm{FL}=(0.8396 \times \mathrm{TL})-3.1902$

One or two whole vertebra from each sample obtained since the previous study were processed for histology as per Natanson et al. (1995). The resulting sections were digitally photographed with an MTI 
CCD 72 video camera ${ }^{1}$ attached to a SZX9 Olympus stereomicroscope using reflected light. Band pairs (consisting of one opaque and one translucent band) were counted and measured using Image Pro 4 software (Media Cybernetics) following the criteria from Natanson et al. (1995). The first opaque band distal to the focus was defined as the birth mark (the birth band radius; BR). A slight angle change in the corpus calcareum coincided with this mark. Measurements were made from the midpoint of the notochordal remnant to the BR and each opaque growth band along the internal corpus calcareum. The vertebral radius (VR) of each centrum was measured to the distal margin of the intermedialia along the same diagonal as band measurements. Samples used in Natanson et al. (1995) were not reprocessed, and the original age estimates were used; however, the BR and VR were remeasured as described above to provide consistency with the current digital analysis system. The identity of the birth band was confirmed by comparing BR values with the VR from young of the year (YOY) and full term embryos (Natanson et al. 2002).

The relationship between VR and FL was derived to determine the best method for back-calculation of size at birth to ensure the proper identification of the birth band. Initial scatterplots of VR and FL indicated a nonlinear relationship; therefore, a linear regression was fitted to log-transformed VR and FL data. Sex was included as a factor; an interaction term was also included to determine whether the slope of the relationship differed between sexes (Zuur et al. 2009). The regression model that best-fit the data was identified from all possible model subsets as the model containing only significant terms $(p<0.05)$ with the smallest second-order Akaike Information Criterion value $\left(\mathrm{AIC}_{\mathrm{c}}\right.$; Burnham and Anderson 2002).

The line did not pass through the origin so we used the Fraser-Lee equation modified for log-transformed data (Natanson et al. 2002) to back-calculate size-atbirth as:

$\ln \left(F L_{a}\right)=b+\ln \left(F L_{c}-b\right) \frac{\ln \left(V R_{a}\right)}{\ln \left(V R_{c}\right)}$,

where $a$ is age; $b$ is the intercept from the FL-VR regression; and $c$ is the age at capture. This and all

\footnotetext{
${ }^{1}$ Reference to Trade Names does not imply endorsement by NMFS.
}

subsequent analyses were conducted in $\mathrm{R}$ ( $\mathrm{R}$ Core Team 2012).

Age determination

Two readers (LJN, BJG) counted sections that were previously assigned ages by Natanson et al. (1995) to ensure consistency of band pair interpretation between studies. Once criteria had been established via intercalibration, each reader independently aged the majority of the samples twice. An additional 30 vertebrae were aged by only the primary reader ( $\mathrm{LJN})$ due to the lack of availability of the second reader. Quality control was maintained by the readers recounting earlier samples prior to initiating each reading and crosschecking the readings.

The consistency of age estimates between ageing rounds and readers was assessed using age bias plots and chi-square tests of symmetry (McNemar 1947; Bowker 1948; Campana et al. 1995; Hoenig et al. 1995; Evans and Hoenig 1998). To resolve discrepancies between readers greater than 2 years, a consensus was reached by reading the centra together. When counts disagreed by only 1 year, the primary reader's age estimates were used.

Bomb radiocarbon validation

Vertebrae from eight individuals were selected based on date of capture, size, and estimated age. Each vertebra was cut transversely through the focus using an Isomet ${ }^{\circledR}$ low speed saw (Buehler, Lake Bluff, IL, USA) equipped with diamond wafering blades which removed a $\sim 4 \mathrm{~mm}$ thick vertebral section. Sections were measured from the central focus to the outer margin and samples were cut along measured increments using a razor blade. Dusky shark vertebrae possess fine banding, making it problematic to extract enough material from individual band pairs in the corpus calcareum for $\Delta^{14} \mathrm{C}$ analysis. Therefore, a single sample consisted of several band pairs encompassing both material from the corpus calcareum and the intermedialia. To verify the location of the samples we compared the measured locations of the samples to measurements from photographs annotated with the band pair counts and then aligned the measured samples with their respective band pairs. 
Band pairs were initially assumed to be annual, and average age was assigned to sample sections based on calculation from catch date. Collagen extraction from vertebral samples was conducted following Tuross et al. (1988). For each sample, approximately $0.5 \mathrm{~g}$ of tissue was soaked overnight in a 3:1 chloroform methanol solution to remove lipids; it was then demineralized at room temperature in EDTA ( $\mathrm{pH}$ 8) for 7-20 days until the sample was soft. Following demineralization, samples were rinsed 10 times in Milli-Q water (with at least one overnight soak), dissolved in Milli-Q water at $110^{\circ} \mathrm{C}$, and filtered through muffled fritted glass filters. The filtrate was frozen and lypholized before the purified collagen was weighed prior to analysis by Accelerator Mass Spectrometry.

The samples for $\delta^{13} \mathrm{C}$ and $\Delta{ }^{14} \mathrm{C}$, with $\Delta{ }^{14} \mathrm{C}$ calculated as per Stuiver and Polach (1977) were analyzed at the National Ocean Sciences Accelerator Mass Spectrometry Facility at the Woods Hole Oceanographic Institution. The resulting dusky shark radiocarbon chronologies were compared to the $\Delta^{14} \mathrm{C}$ signal in the Atlantic as recorded by two reference chronologies, one from coral in Bermuda (Druffel 1989), and one from fish otoliths in the northwest Atlantic (Campana et al. 2008). Where reference chronologies and vertebral data differed, vertebral data were shifted back until they aligned with the reference data (Francis et al. 2007; Andrews et al. 2011). This was necessary for two specimens (DS51 and DS81).

\section{Growth curve estimation}

Length-at-age estimates based upon observed band pair counts were fitted using the Schnute (1981) growth model. The general model requires the specification of two reference ages, $t_{1}$ and $t_{2}$, and has the following four parameters:

\section{$L_{1} \quad$ length at age $t_{1}$,}

$L_{2} \quad$ length at age $t_{2}$,

a a constant $\left(\right.$ time $^{-1}$ ) describing the constant relative rate of the relative growth rate,

$b$ a dimensionless constant describing the incremental relative rate of the relative growth rate.

Reference ages were set at $t_{1}=1$ year and $t_{2}=25$ year.
The general model is specified as:

$L_{t}=\left[L_{1}^{b}+\left(L_{2}^{b}-L_{1}^{b}\right) \frac{1-e^{-a\left(t-t_{1}\right)}}{1-e^{-a\left(t_{2}-t_{1}\right)}}\right]^{\frac{1}{b}}$,

where $a \neq 0, b \neq 0$.

The model takes several forms based on the values of $a$ and $b$. Not all of the forms (which include linear and exponential growth) were appropriate for our data; therefore we focused on three special cases, which are equivalent to the specialized von Bertalanffy (VBGF; von Bertalanffy 1938), Gompertz (Ricker 1975), and logistic growth models (Ricker 1979) commonly reported in elasmobranch age and growth studies. The general model is equivalent to the VBGF when $a>0$ and $b=1$; it takes the logistic form when $a>0$ and $b=-1$. The Gompertz function is expressed as:

$L_{t}=L_{1} e^{\ln \left(\frac{L_{2}}{L_{1}}\right) \frac{1-e^{-a\left(t-t_{1}\right)}}{1-e^{-a\left(t_{2}-t_{1}\right)}},}$

where $a>0, b=0$.

To investigate potential changes in growth parameters over time, samples were classified into population size periods based on date of capture as pre- or postpopulation depletion. Specimens collected between 1963 and 1989 (the year in which peak commercial landings of large coastal and pelagic sharks were reported; NMFS 2011) were categorized as pre-depletion; those collected from 1990 onward were considered post-depletion.

While selecting such an abrupt point in time does not take into account the long generation time of the species (Cortés 2002), we were constrained by our sample size. To account for potential lag time in the species' response given its life history characteristics, we also compared growth prior to (19631994; hereafter referred to as Period A, TPA) and postmanagement (2005-2010; Period B, TPB). These periods were based on obtaining a 10 year hiatus between collections to enable us to compare pre- and postmanagement.

Parameter estimates for each growth function were estimated using nonlinear least-squares regression methods in R ( $\mathrm{R}$ Core Team 2012). Models with common parameter estimates between sexes, population sizes (pre- or post-depletion), and management periods (TPA and TPB) were compared to those with separate 
parameter estimates to determine if there was evidence of difference. While this is typically presented as a two-part analysis in elasmobranch age and growth studies, it is really a question of overall model selection (e.g. Does the inclusion of separate parameter estimates for each sex improve model fit, or can growth be sufficiently described using common parameter estimates for both sexes?). If the inclusion of separate parameters produced a better fit than the model with common parameters, this was considered evidence of difference.

Final model selection was based on statistical fit and compatibility with known biological parameters. Model goodness-of-fit was evaluated by the small-sample, bias-corrected form of the Akaike information criterion $\left(\mathrm{AIC}_{\mathrm{c}}\right.$; Akaike 1973; Burnham and Anderson 2002). The $\mathrm{AIC}_{\mathrm{c}}$ provides a measure of model fit and complexity and allows for the simultaneous comparison of growth models and their subsets, with the model with the smallest $\mathrm{AIC}_{\mathrm{c}}$ value considered the "best" out of the suite of models considered. The $\mathrm{AIC}_{\mathrm{c}}$ difference $\left(\Delta_{i}\right)$ of each model was calculated based on the lowest observed $\mathrm{AIC}_{\mathrm{c}}$ value $\left(\mathrm{AIC}_{\mathrm{c}, \text { min }}\right)$ as $\Delta_{i}=\mathrm{AIC}_{\mathrm{c}, \mathrm{i}}-\mathrm{AIC}_{\mathrm{c} \text {,min }}$ to provide an estimate of the magnitude of difference between each model and the best model in the set. Models with values of $\Delta_{\mathrm{i}}>10$ were considered as having essentially no support and were omitted from further consideration. Models with $\mathrm{AIC}_{\mathrm{c}}$ values differing by $<2$ were considered indistinguishable; in such cases the most parsimonious model was selected (Burnham and Anderson 2002). To approximate model likelihood, the Akaike weight $\left(w_{i}\right)$ of each model was also calculated (Burnham and Anderson 2002).

Ninety-five percent confidence intervals were constructed for parameter estimates via bootstrap methods using the "nlstools" package in R (Baty and DelignetteMuller 2011). Residual plots were inspected to ensure the assumptions of homoscedasticity and normality of the error terms were met (Zuur et al. 2009). Parameter estimates typically reported for the three models (e.g. asymptotic size, $L_{\infty}$; theoretical size at birth, $t_{0}$; and the growth coefficient, $k$ ) were calculated following Schnute (1981) for comparison with other studies. Length-at-birth $\left(L_{0}\right)$ was estimated from the resulting equation for each growth model.

Growth curves using only validated data were generated for comparison with curves based on vertebral band pair counts. All samples over the highest age for which annual band pair deposition was validated (10.7 year; see
"Results") were removed from the dataset, leaving only three larger individuals with directly validated ages (2 male and 1 female). The limited number of older individuals precluded comparison of parameters between sexes, population sizes, or time periods.

\section{Results}

Vertebral interpretation

Vertebral samples from 251 free-living and 18 embryonic dusky sharks were used in this study. The 138 female and 113 male free-living sharks ranged in size from $74 \mathrm{~cm}$ to $300 \mathrm{~cm}$ FL. Embryos ranged in size from $48 \mathrm{~cm}$ to $66 \mathrm{~cm}$ FL. One hundred and sixty samples (63 male, 74-276 cm FL; 97 female, 76-287 cm FL) were collected during TPA and 63 (38 male, 78-264 cm FL; 25 female, 78-270 cm FL) during TPB; all 18 embryos were sampled in TPA. An additional 16 females (82$300 \mathrm{~cm} \mathrm{FL}$ ) and 12 males (85-260 cm FL) were obtained from 1995 to 1998 . When samples were categorized by population size, 127 samples were obtained pre- (51 male, 74-276 cm FL; 76 female, 77-287 cm FL) and 124 post-depletion ( 62 male, $77-264 \mathrm{~cm} \mathrm{FL}$; 62 female, 76-300 cm FL).

The location of the BR, between the VR of late term embryos and YOY, indicated the birth band was identified correctly $(\mathrm{BR}=4.55 \pm 0.05$ (mean $\pm 95 \% \mathrm{CI}) ; n=$ 186; VR=3.45 $\pm 0.10, n=18$ embryos; $\mathrm{VR}=4.77 \pm 0.16$, $n=34$ YOY). There was no evidence of difference in the FL-VR relationship between the sexes based on $\mathrm{AIC}_{\mathrm{c}}$ values $\left(\mathrm{AIC}_{\mathrm{c}} \mathrm{VR}=-746.56 ; \mathrm{AIC}_{\mathrm{c}} \mathrm{VR}+\mathrm{Sex}=\right.$ $-745.64 ; \mathrm{AIC}_{\mathrm{c}} \mathrm{VR}^{*} \mathrm{Sex}=-746.73 ; \Delta_{\mathrm{i}}<2.0$ in all cases). The FL-VR relationship was described for both sexes as follows:

$\ln (F L)=0.83 \ln (V R)+3.15\left(\mathrm{n}=248 ; r^{2}=0.99\right)$

The back-calculated size at birth based on the mean BR of the sample was $82.1 \mathrm{~cm}$ FL (71.5-95.0 cm FL) (Fig. 1).

Age determination

Comparison of counts indicated that both readers were identifying the same band pairs. Sixty-six percent of counts agreed between readers and $89.5 \%$ were within one band pair. Only 11 counts differed by greater than 


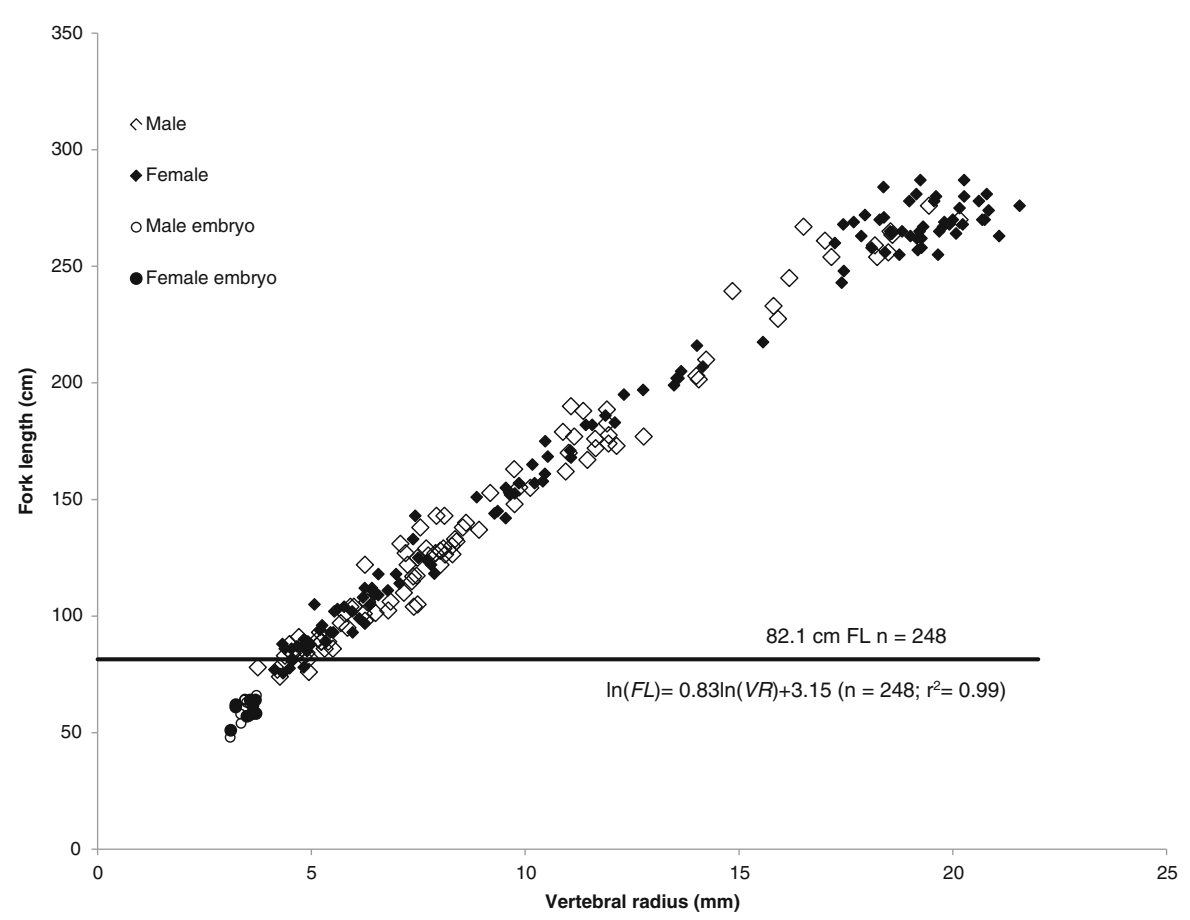

Fig. 1 Relationship between vertebral radius and fork length for male and female dusky sharks. The horizontal lines represents the size at birth

one band pair, with three samples needing to be aged by consensus. An age bias plot showed minimal variation around the 1:1 plot and no systematic bias (Fig. 2a). Additionally, the Bowker $\left(\chi^{2}=19.20, d f=23\right.$, $n=105, p=0.69)$, McNemar $\left(\chi^{2}=1.17, d f=4, n=105\right.$, $p=0.88)$ and Evans- Hoenig $\left(\chi^{2}=0.00, d f=1, n=105, p=\right.$ $1.00)$ chi-square tests of symmetry gave no indication that differences between readers were systematic rather than due to random error. Comparison of the first and second counts of the first reader also indicated no systematic bias Bowker $\left(\chi^{2}=25.00, d f=25, n=100, p=0.46\right)$, McNemar $\left(\chi^{2}=9.80, d f=6, n=100, p=0.13\right)$ and Evans-Hoenig $\left(\chi^{2}=\right.$ 3.46, $d f=1, n=100, p=0.06$ ) (Fig. 2b).

Bomb radiocarbon validation

A total of 30 samples were extracted from the eight sharks selected for radiocarbon analysis. The $\delta^{13} \mathrm{C}$ values (mean $\pm \mathrm{SE}=-12.68 \%{ }_{0} \pm 0.101 \%$ o) of the samples were typical of metabolically derived carbon (Kalish and Johnston 2001; Campana et al. 2002). Radiocarbon values ranged from $-84.2 \%$ o to $99.9 \%$ o $\Delta^{14} \mathrm{C}$, which correspond to the years 1949.5 and 1984 , respectively.
Vertebral data from the six smallest sharks appeared to line up with the reference curves (Fig. 3a), indicating that band pair counts were annual up to age 11 (Table 1). $\Delta^{14} \mathrm{C}$ values of two male sharks in the post-bomb period were intermediate between the Bermuda and northwest Atlantic radiocarbon curves (Fig. 3a). Though the DS234 chronology followed a reasonable declining trajectory, it recorded only post-bomb spike material (Fig. 3a), rendering it ineffective for validating counts.

The two largest sharks (DS51 \& DS81) appeared to be substantially under-aged, as their radiocarbon records were shifted to the right of the bomb radiocarbon spike in the reference chronologies (Fig. 3b). In order to align $\Delta^{14} \mathrm{C}$ values with the corresponding values from the reference chronologies and the other shark chronologies, age estimates were increased by 15 (DS51) and 19 (DS81) years, resulting in an estimated age at capture of 38 and 42 years, respectively (Fig. 3c).

Growth curve estimation

Based on $\mathrm{AIC}_{\mathrm{c}}$ values, the best fitting model for band pair counts of all samples collected throughout the course of the study $(n=251)$ was the logistic form of the Schnute model incorporating separate parameter 


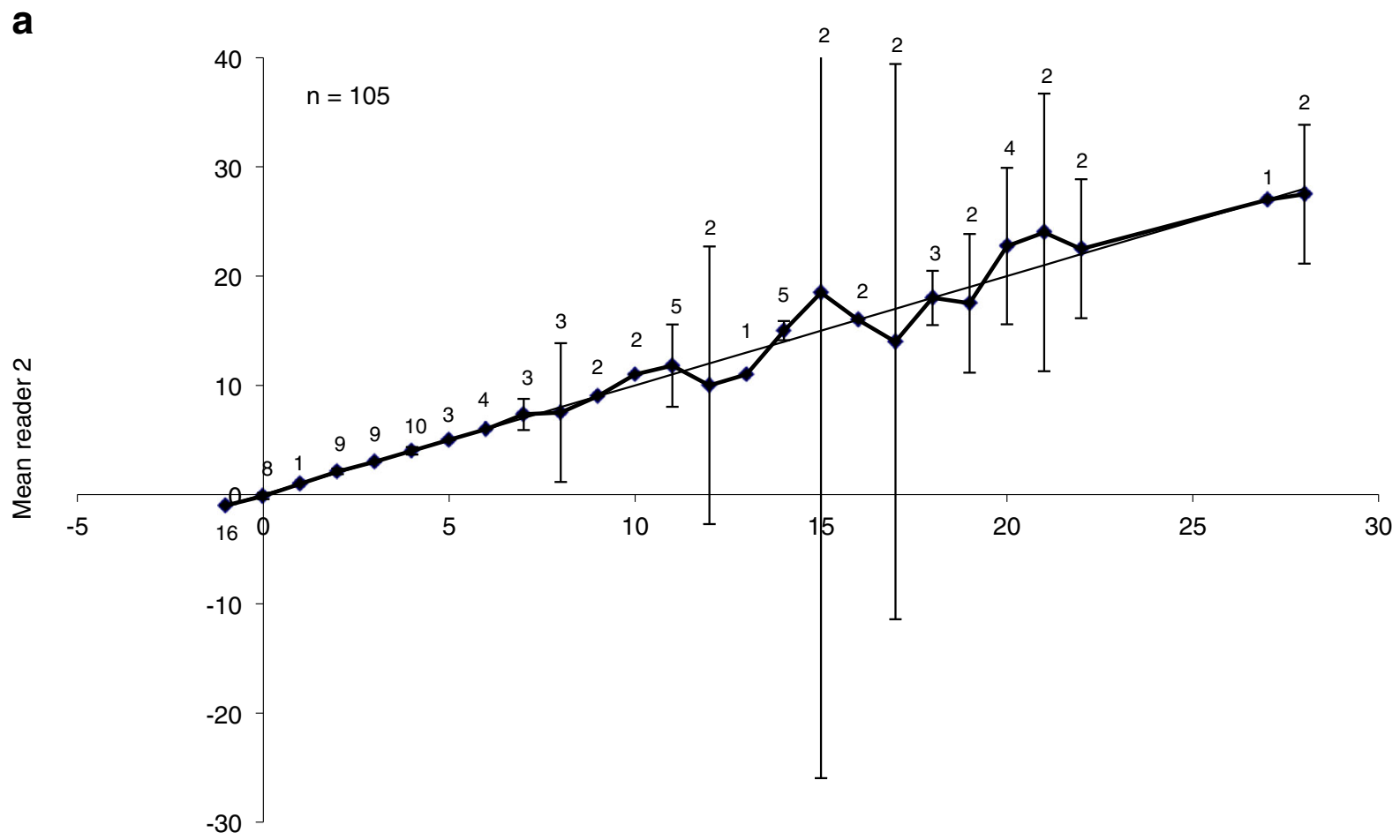

Reader 1

b

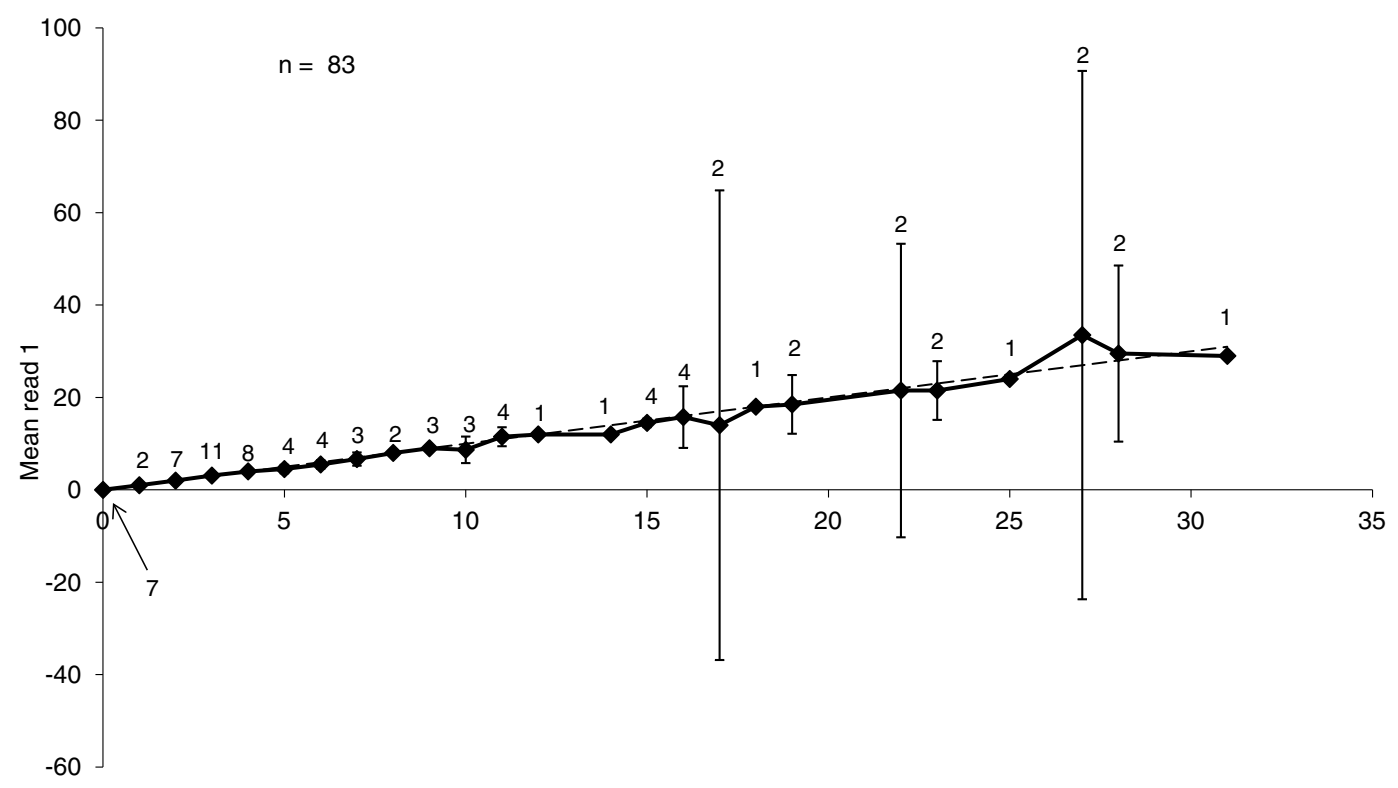

Read 2

Fig. 2 Age bias graph for pair-wise comparison of a) 105 dusky shark vertebral counts from the second count of two independent age readers. Each error bar represents the $95 \%$ confidence interval for the mean age assigned by reader 2 to all fish assigned a given age by reader 1; and b) 83 dusky sharks from the primary reader. Each error bar represents the $95 \%$ confidence interval for the mean age assigned on the first read to all fish assigned a given age on the second read. The one to one equivalence line is also presented 
Fig. 3 a) Bomb radiocarbon results from six dusky shark vertebrae that did not require shifting, the northwest Atlantic $\Delta^{14} \mathrm{C}$ otolith reference chronology, and the Bermuda $\Delta^{14} \mathrm{C}$ coral reference chronology. b) Bomb radiocarbon results from two dusky shark vertebrae and reference chronologies as in (a). Arrows indicate vertebral $\Delta^{14} \mathrm{C}$ curves that had to be shifted to line up with reference chronologies (dashed lines are initial data, solid lines are data shifted to align with the references). c) Bomb radiocarbon results from all 8 dusky shark vertebrae including adjusted chronologies as in (b), and reference chronologies as in (a) a

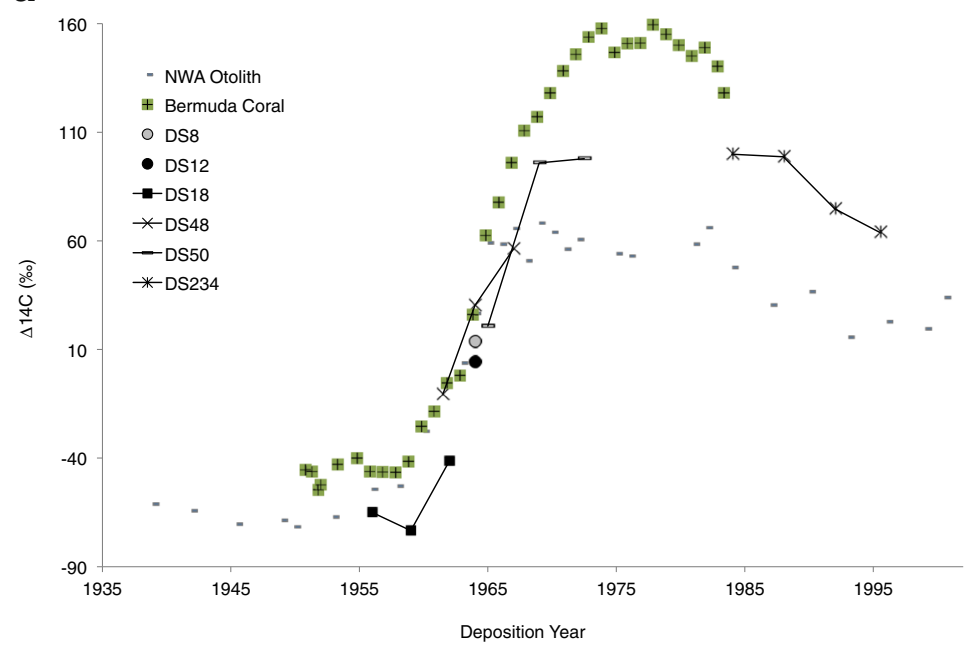

b

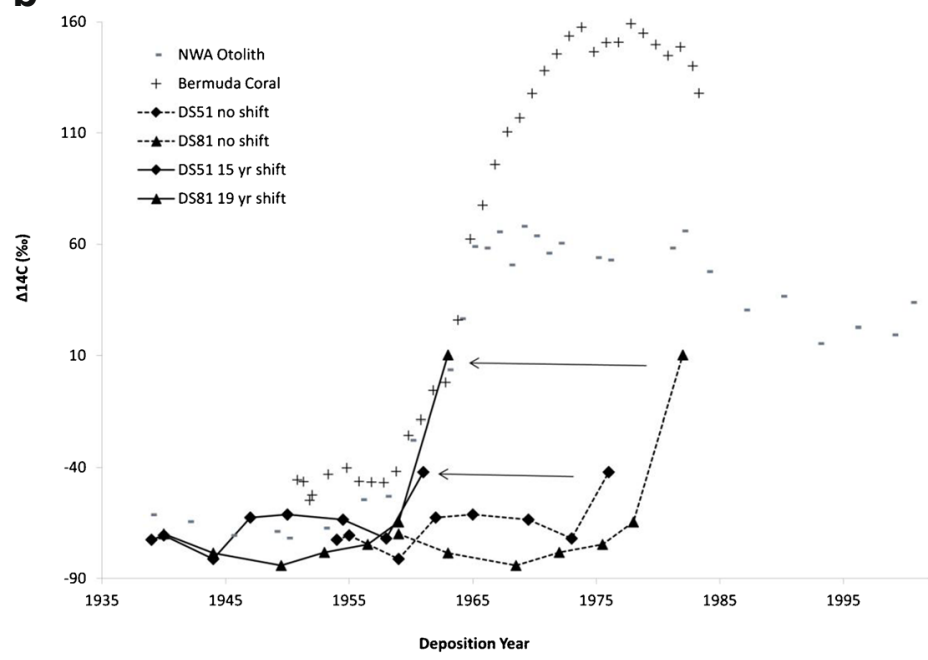

C

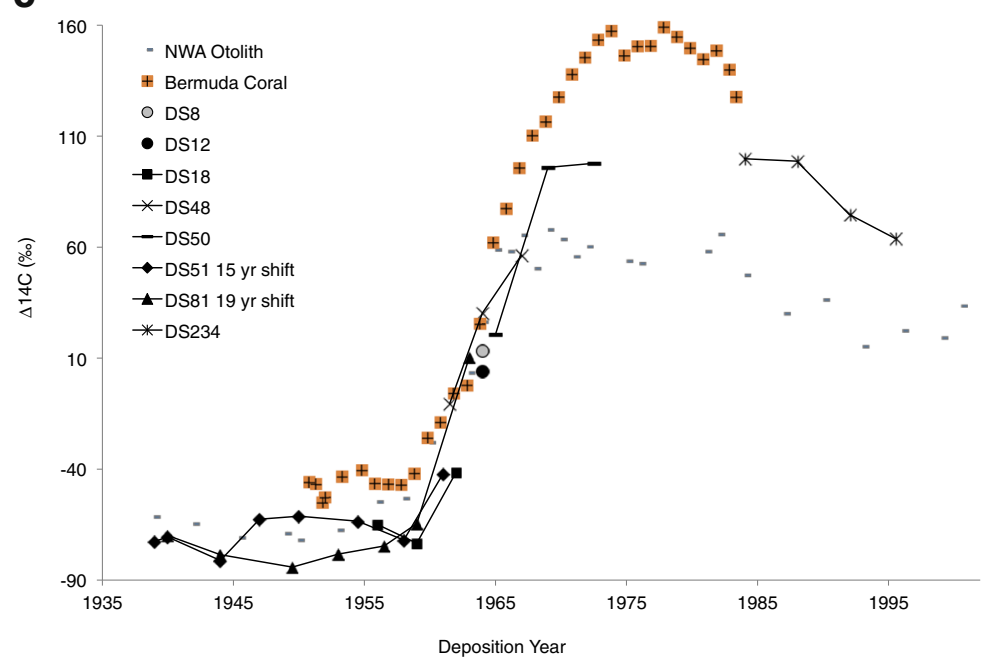


Table 1 Summary of individual shark information for vertebrae used for radiocarbon analyses

\begin{tabular}{llllll}
\hline Shark & Year collected & FL $(\mathbf{c m})$ & Sex & $\Delta^{\mathbf{1 4}}$ C Age & Band pairs \\
\hline DS8 & 1965 & 95 & M & 1 & 1 \\
DS12 & 1965 & 102 & F & 1 & 1 \\
DS18 & 1964 & 148 & M & 9 & 9 \\
DS48 & 1969 & 174 & M & 8 & 8 \\
DS50 & 1975 & 177 & M & 11 & 11 \\
DS51 & 1977 & 263 & F & 38 & 23 \\
DS81 & 1982 & 259 & M & 42 & 23 \\
DS234 & 1997 & 218 & M & 15 & 15 \\
\hline
\end{tabular}

Discrepancies between band pairs and $\Delta^{14} \mathrm{C}$ age indicate instances where a shift was necessary to align sample $\Delta^{14} \mathrm{C}$ values to reference curves (shaded rows). FL fork length

estimates for each sex (Table 2a). Including separate parameter estimates for each population size (pre- and postdepletion) did not improve fit over any of the models incorporating common parameter estimates, with the exception of the von Bertalanffy. However, $\Delta_{i}$ values for all versions of the von Bertalanffy were $>10$, suggesting that the models had essentially no support (Burnham and Anderson 2002) and rendering the difference meaningless (Haddon 2001). More detailed analysis of the model subsets indicated that the best fitting models $\left(\Delta_{\mathrm{i}}<2.0\right.$; Table 3a) contained common parameter estimates for $l_{1}$ and $l_{2}$ but separate estimates for $a$.

When the analysis was restricted to the samples collected during the pre-and post-management periods, the logistic model incorporating separate parameter estimates for each sex remained the best fitting (Table 2b). Including separate parameter estimates for each management period did not improve fit over any of the models incorporating common parameter estimates (Table 3b). Again, more detailed analysis of logistic model parameters suggested that $a$ was the source of difference between the sexes (Table 3b). Therefore, sexes were evaluated separately for the rest of this analysis but time periods were not, allowing us to use age estimates from specimens collected over the entire course of the study to generate growth curves.

Based on vertebral band pair counts, female growth was best described by the logistic model (Table 4; Fig. 4a) and male growth by the Gompertz (Table 4; Fig. 4b), although it should be noted that differences between models fit to male data were minimal. Validated growth $(n=152)$ was best described by the logistic function (Table 4; Fig. 5). The validated growth curve predicted a lower asymptotic length and correspondingly smaller sizes at age (Fig. 5).

\section{Discussion}

The under-ageing of long-lived elasmobranch species using band pairs on vertebral centra has become increasingly apparent. Since 2001, twelve studies have applied bomb radiocarbon dating to elasmobranchs (Kalish and Johnston 2001; Campana et al. 2002; Ardizzone et al. 2006; Campana et al. 2006; Kerr et al. 2006; Francis et al. 2007; Kneebone et al. 2008; McPhie and Campana 2009; Passerotti et al. 2010; Andrews et al. 2011; Tillet et al. 2011; Present study). Of these studies, five have shown that band pairs are deposited annually for only a portion of the life span of a species or could not validate the ages (Kalish and Johnston 2001; Kerr et al. 2006; Francis et al. 2007; Andrews et al. 2011; Present study). This finding calls into question the value of elasmobranch age determination based on band pair counts of vertebral centra.

Several possible explanations have been put forth to explain why the vertebral counts underestimate actual ages. These include difficultly discerning band pairs at the growing edge due to slower growth in older individuals, decreased or lack of band pair deposition following maturation, or deposition related to somatic growth and reproduction rather than seasonal cues (Natanson and Cailliet 1990; Natanson 1993; Francis et al. 2007; Natanson et al. 2008). Using histology, the 
Table 2 Relative goodness-of-fit for each growth model for Carcharhinus obscurus from the northwestern Atlantic for A) unvalidated band pair counts from 1963 to $2010(n=251)$ and B) unvalidated band pair counts from 1963-1994 to 2005-2010 ( $n=223)$

\begin{tabular}{llllll}
\hline Model & $\mathrm{k}$ & $\mathrm{AIC}_{\mathrm{c}}$ & $\Delta_{\mathrm{i}}$ & $\mathrm{w}_{\mathrm{i}}$ \\
\hline
\end{tabular}

A)

\begin{tabular}{lrrrr} 
Logistic + sex & 7 & 1942.27 & 0.00 & 0.76 \\
Logistic & 4 & 1945.70 & 3.43 & 0.14 \\
Gompertz + sex & 7 & 1946.87 & 4.60 & 0.08 \\
Logistic + population size & 7 & 1950.55 & 8.29 & 0.01 \\
Gompertz & 4 & 1951.17 & 8.90 & 0.01 \\
Gompertz + population size & 7 & 1954.23 & 11.97 & 0.00 \\
von Bertalanffy + sex & 7 & 1965.19 & 22.93 & 0.00 \\
von Bertalanffy + population size & 7 & 1971.50 & 29.24 & 0.00 \\
von Bertalanffy & 4 & 1973.14 & 30.88 & 0.00 \\
B) & & & & \\
Logistic + sex & 7 & 1722.42 & 0.00 & 0.69 \\
Logistic & 4 & 1724.71 & 2.29 & 0.22 \\
Gompertz + sex & 7 & 1727.94 & 5.52 & 0.04 \\
Logistic + time period & 7 & 1728.27 & 5.85 & 0.04 \\
Gompertz & 4 & 1732.69 & 10.28 & 0.00 \\
Gompertz + time period & 7 & 1737.25 & 14.83 & 0.00 \\
von Bertalanffy + sex & 7 & 1745.45 & 23.03 & 0.00 \\
von Bertalanffy & 4 & 1754.50 & 32.08 & 0.00 \\
von Bertalanffy + time period & 7 & 1756.69 & 34.27 & 0.00 \\
\hline & & & & \\
\hline
\end{tabular}

Models are ranked from best to worst fitting. + indicates the incorporation of a factor with separate parameter estimates for each level of the factor (Sex = male or female, Population Size = pre- or post-depletion, Time Period = pre- or post- management). Models without factors incorporated common parameter estimates for the entire dataset. If the inclusion of a factor produced a better fit than the model with common parameters, this was considered as evidence of difference in the parameter estimates between factor levels. See text for details. $-\mathrm{k}=$ total number of regression parameters, which includes the error term; $\mathrm{AIC}_{\mathrm{c}}=$ the small-sample, bias corrected form of the Akaike information criterion; $\Delta_{i}=$ Akaike difference, $\mathrm{w}_{\mathrm{i}}=$ Akaike weight

band pairs along the centra and at the edge are clear and easily countable; thus, difficulty discerning band pairs is not the underlying issue (James et al. 2013). In fact, in the current study and in Andrews et al. (2011) more band pairs could be counted; however, these "extra" band pairs did not meet the criteria whereby the ages of juveniles were validated. This indicates that a decrease in band pair deposition, whether related to somatic growth or maturity, is more likely the cause. While experimentation to determine these factors is difficult, it has been shown in two unrelated species that band pair deposition
Table 3 Relative goodness-of-fit with separate parameter estimates for each sex for the logistic growth model for Carcharhinus obscurus from the northwestern Atlantic for A) unvalidated band pair counts from 1963 to $2010(n=251)$ and B) unvalidated band pair counts from 1963-1994 to 2005-2010 $(n=223)$

\begin{tabular}{lllll}
\hline Model & $\mathrm{k}$ & $\mathrm{AIC}_{\mathrm{c}}$ & $\Delta_{\mathrm{i}}$ & $\mathrm{w}_{\mathrm{i}}$ \\
\hline A) & & & & \\
Common $l_{l}$ and $l_{2}$ & 5 & 1938.99 & 0.00 & 0.38 \\
Common $l_{1}$ & 6 & 1940.22 & 1.23 & 0.21 \\
Common $l_{2}$ & 6 & 1941.06 & 2.07 & 0.14 \\
Common $a$ & 6 & 1942.20 & 3.21 & 0.08 \\
Common $a$ and $l_{1}$ & 5 & 1942.23 & 3.24 & 0.08 \\
Separate & 7 & 1942.27 & 3.28 & 0.07 \\
Common $a$ and $l_{2}$ & 5 & 1943.51 & 4.52 & 0.04 \\
Common & 4 & 1945.70 & 6.71 & 0.01 \\
B) & & & & \\
Common $l_{l}$ and $l_{2}$ & 5 & 1718.22 & 0.00 & 0.48 \\
Common $l_{2}$ & 6 & 1720.28 & 2.07 & 0.17 \\
Common $l_{l}$ & 6 & 1720.33 & 2.11 & 0.17 \\
Separate & 7 & 1722.42 & 4.20 & 0.06 \\
Common $a$ and $l_{2}$ & 5 & 1722.48 & 4.27 & 0.06 \\
Common $a$ & 6 & 1723.88 & 5.67 & 0.03 \\
Common & 4 & 1724.71 & 6.49 & 0.02 \\
Common $a$ and $l_{1}$ & 5 & 1724.94 & 6.72 & 0.02 \\
\hline
\end{tabular}

Models are ranked from best to worst fitting. The 'separate' model incorporated different parameter estimates for each sex. The 'common' model incorporated the same parameter estimate for males and females. All other model subsets contained a mix of common and separate parameters as indicated. $a, l_{1}$, and $l_{2}$ are the logistic growth model parameters; $\mathrm{k}=$ total number of regression parameters, which includes the error term; $\mathrm{AIC}_{\mathrm{c}}=$ the small-sample, bias corrected form of the Akaike information criterion; $\Delta_{i}=$ Akaike difference, $\mathrm{w}_{\mathrm{i}}=$ Akaike weight

is related to somatic growth (Natanson and Cailliet 1990; Natanson et al. 2008). Additionally, in the little skate, Leucoraja erinacea, seasonal temperature cues had no effect on deposition rate but active reproduction did decrease band pair deposition (Natanson 1993).

Band pair counts for dusky sharks underestimated true age by as much as 19 years in individuals older than 11 years; other current studies suggest this phenomenon occurs more widely than previously assumed. Andrews et al. (2011) reported similar results for the closely related sandbar shark, finding band pair counts accurate only to $10-12$ years and resulting in underageing thereafter. For the white shark, Carcharodon carcharias, in the northwest Atlantic, Hamady et al., 


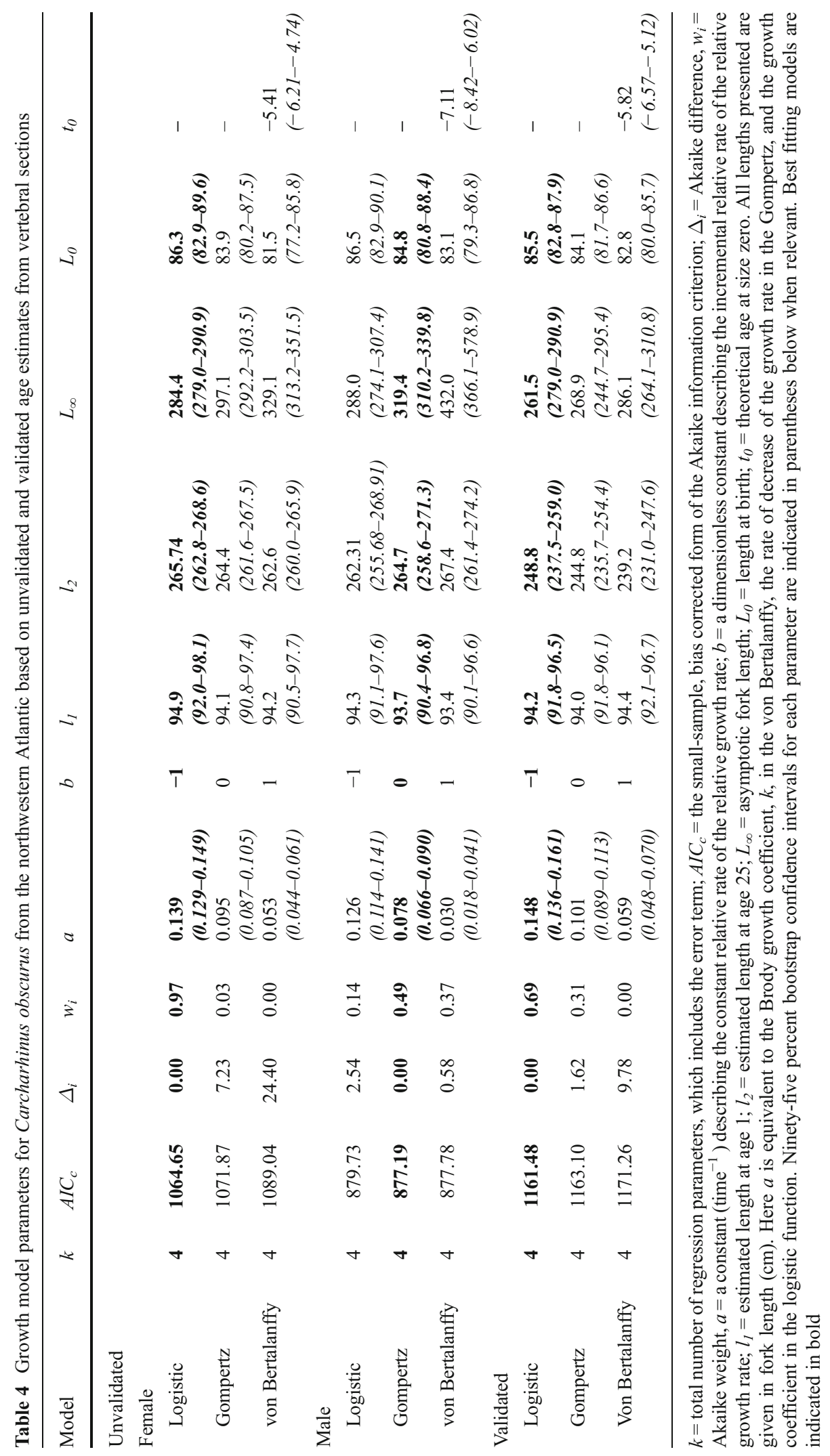




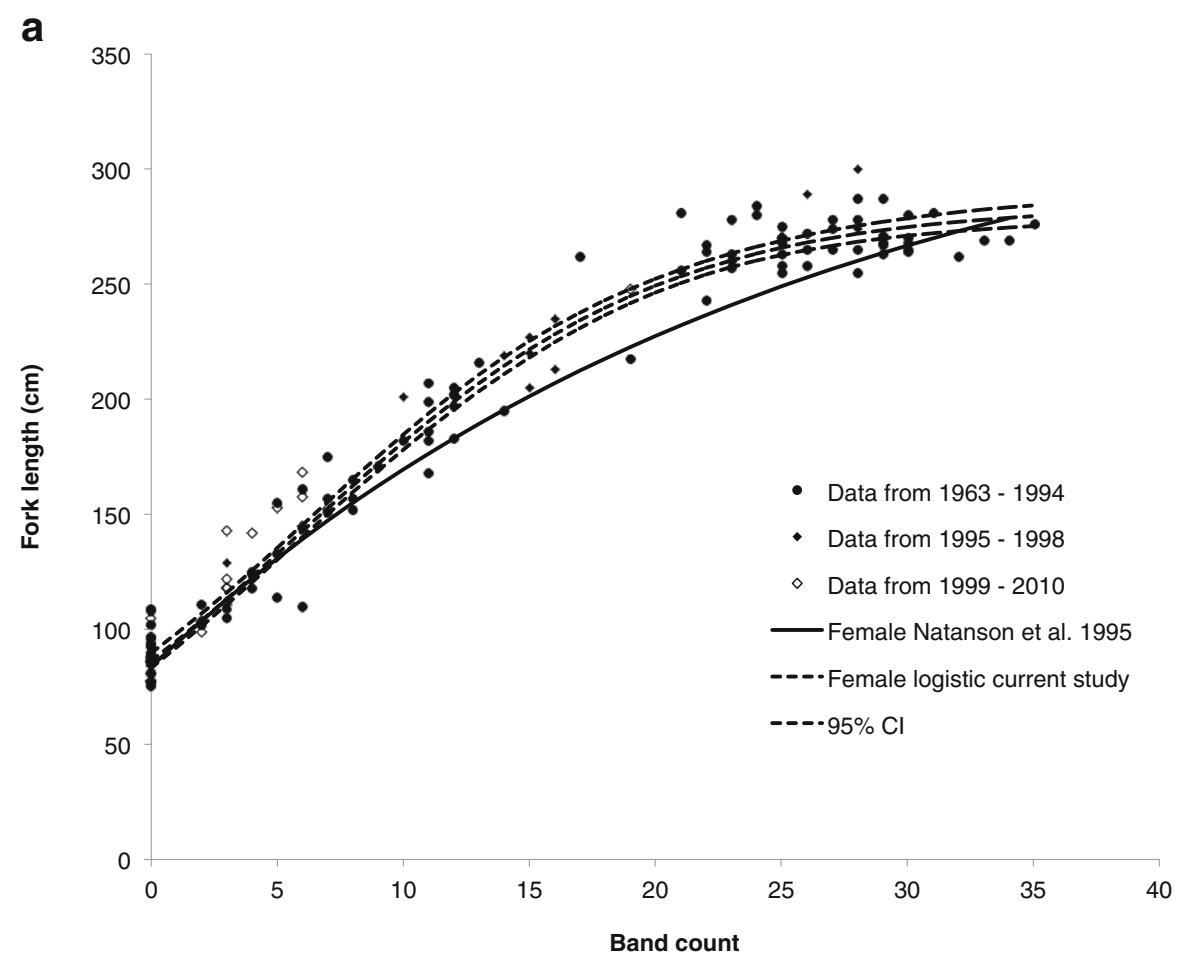

b

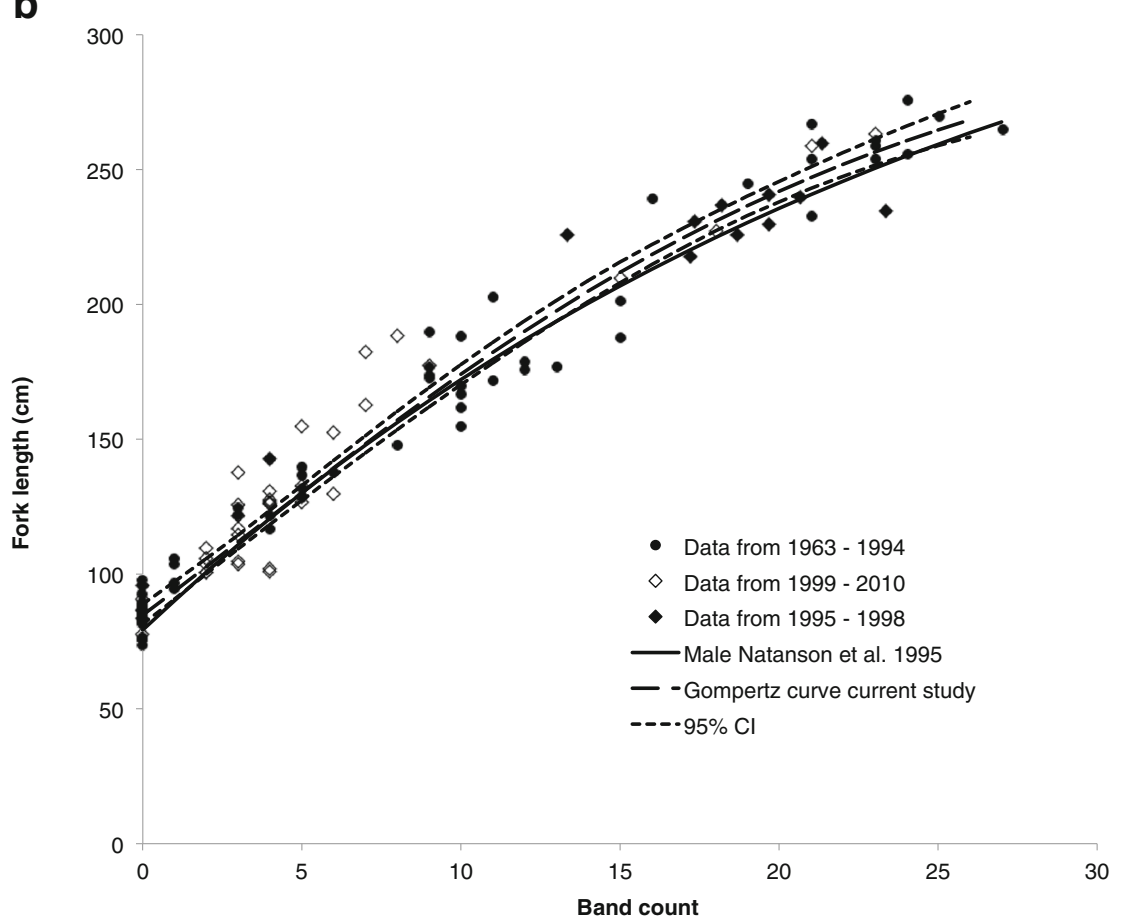

Fig. 4 Dusky shark growth data based on vertebral band counts. Logistic growth curve have been fitted to the female data (a) and Gompertz growth function has been fit to the male data (b). All data are presented as are growth curves from a previous study (Natanson et al. 1995) 


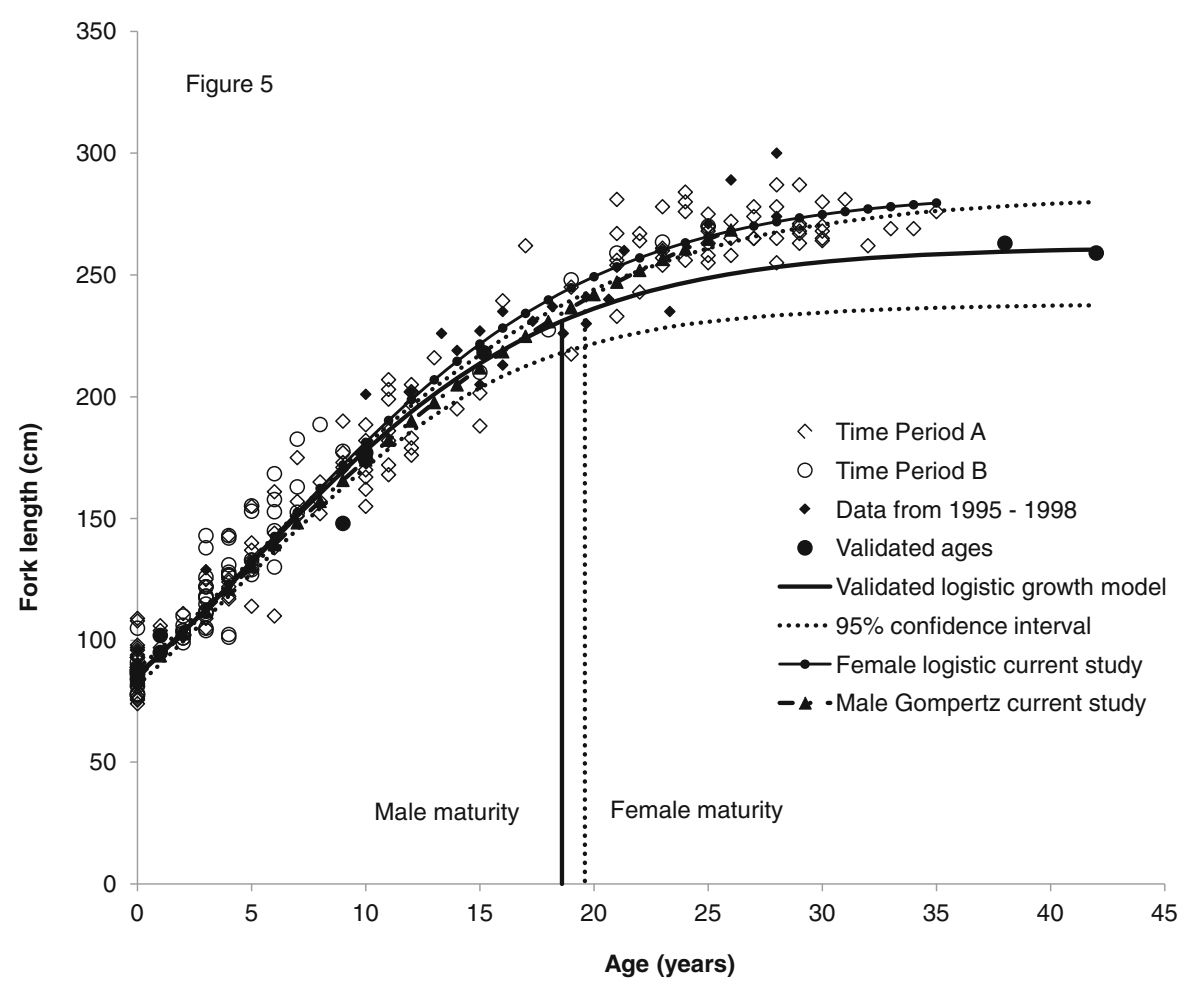

Fig. 5 Validated dusky shark growth data. Ninety-five percent confidence intervals and band pairs counts by period are also plotted

(Bomb Radiocarbon Confirmation of Extreme Longevity in White Sharks (in review)) found a similar result for male sharks. In contrast, female band pair counts overestimated age, indicating sexual dimorphism in band pair deposition (Hamady et al., Bomb Radiocarbon Confirmation of Extreme Longevity in White Sharks (in review)). Similarly, a study on porbeagle sharks, Lamna nasus, off New Zealand showed that validated ages were higher than band pair counts, suggesting deposition either stopped when somatic growth ceased or that band pairs were irresolvable at the vertebral margin (Francis et al. 2007). Little skates stopped depositing annual band pairs while reproductively active (Natanson 1993). More recently, Harry et al. (2013) showed that pregnant female $C$. sorrah did not uptake calcein on the growing edge, though male and nonpregnant females did, suggesting that the reproductively active females of this species may stop band pair deposition during pregnancy.

Given the importance of accurate age estimation to population assessment, validation of the periodicity of vertebral growth band deposition must be performed for all species of management interest. While the validated growth curve for the dusky shark is based on a small number of larger specimens, it represents the best available estimate at this time. The use of incorrect ages and resulting growth rates in demographic analyses can lead to errors in estimates of natural mortality rates, population growth rates, and management actions based upon those estimates (Beamish and McFarlane 1983; Cailliet and Andrews 2008). Given the high management profile of the species, age and growth parameters from the validated curves should be used as the basis for the species until more samples can be processed and the estimates refined.

When only validated age estimates were used for growth curve fitting, parameter estimates were not substantially different from those based on all band pair counts, reinforcing the conclusions of Natanson et al. (1995). These authors directly aged one dusky shark at $33^{+}$from vertebral band pair counts and estimated another at 39 years from tag/recapture analysis; theoretical longevities based on the von Bertalanffy growth model ranged from 40 to 50 years. They calculated that the largest reported dusky (308 cm FL female; Springer 1960) could be 51 years based on their growth curve. In this study, direct validation was obtained on a 38 year old female and a 42 year old male. These were the oldest 
of the validated samples but were not the largest individuals collected over the course of the study, suggesting that the species likely obtains higher ages.

The age at $50 \%$ maturity for females and males was estimated at 17.6 and 17.4 years, respectively, based on the validated growth curve and the estimated size at $50 \%$ maturity $(227 \mathrm{~cm} \mathrm{FL}$ and $226 \mathrm{~cm}$ FL female and male, respectively; J. Romine pers. comm. ${ }^{2}$ ). Refinements in both the maturity estimates by Romine (pers. comm. ${ }^{2}$ ) and the new growth curve have lead to a decrease in these estimates since the 19 and 21 year maturity estimates for males and females, respectively, by Natanson et al. (1995).

Given the severe decline in abundance experienced by the dusky shark in the northwestern Atlantic, one would expect to observe changes in life history parameters over time as a compensatory density-dependent response (Rose et al. 2001). However, the current study showed no evidence of difference in the size-at-age relationship between pre- and post- population depletion or management periods. By maintaining the same processing procedures, band pair criteria, and band pair reader between the two periods, potential bias associated with vertebral preparation and interpretation was minimized and, therefore, unlikely to effect the results (Cailliet et al. 1990).

Unfortunately, given the opportunistic nature of our sampling scheme, the potential for gear or area effects cannot be ruled out. However, the size range of the species was represented in all time periods, and geographic variation in parameters due to genetic effects is likely to be minimal; all samples used in this study were likely obtained from the same population of dusky sharks (Benavides et al. 2011). Thus, while we acknowledge that there are limitations to these analyses in terms of sample sizes and frequency distributions, we also feel it would have been remiss not to test for density-dependant differences due to the exploitation history of this species. Additionally, the use of unvalidated ages for the comparison may have confounded results; however, inspection of the plotted size-at-age data in the range of validated ages $(<10.7$ year, Fig. 5) indicates no obvious difference between periods.

While density-dependence is a common term in fisheries science, the ability to measure its magnitude in a population is highly controversial (Rose et al. 2001). Density-mediated changes in life history parameters

\footnotetext{
$\overline{2}$ J. Romine 2013 Pers. Comm. 5501-A Cook-Underwood Road, Cook, WA 98605-9717
}

have been reported for four other shark species following extended exploitation. In the northwestern Atlantic, changes in both the growth rate and age at maturation were observed in the porbeagle (Cassoff et al. 2007). Evidence of change in the growth rate of juvenile sandbar sharks has also been reported (Sminkey and Musick 1995). Changes in life history parameters have also been documented for spiny dogfish, Squalus acanthias, in the northeast Pacific Ocean (Taylor and Gallucci 2009) and the Atlantic sharpnose shark in the Gulf of Mexico (Carlson and Baremore 2003). The relative lack of reported instances among elasmobranchs when compared to teleosts (Rose et al. 2001) illustrates the difficulty of documenting such effects in long lived species with correspondingly long generation times and recovery periods (Cortés 2002).

Differences in life history parameters and study timescales may explain why changes were observed over time in the above species but not in the dusky shark. The porbeagle and Atlantic sharpnose are both faster growing species with shorter life spans (Campana et al. 2002; Natanson et al. 2002; Carlson and Baremore 2003) and are likely able to more rapidly compensate for density related changes due to shorter generation times (Cortés 2002). The relatively broad periods defined as pre(1963-1989) and post- depletion (1990-2010) and pre-management for the purposes of this study (19631994) spanned the intensification, peak, and decline of the U.S. Atlantic coastal shark fishery and may have masked changes that occurred within those years; unfortunately, sample size constraints prevented us from splitting the data into smaller intervals. However, the long life span and generation time of the species would likely dampen the magnitude of any such short-term changes occurring within that period; multi-generational timescales may be required to detect density-related trends (Sæther et al. 2005; Taylor and Gallucci 2009). It is also important to note that environmental changes may also play a confounding role in discerning density-mediated changes (Rose et al. 2001); teasing apart the contribution of large-scale environmental and density-dependent effects to observed trends is an important and complicated area of future research (Taylor and Gallucci 2009).

The increasing evidence that band pair deposition does not remain annual throughout the life of many elasmobranch species makes examining density-dependent effects on growth difficult. Without known ages, it is not possible to look for changes in those ages; therefore, we suggest that no conclusions can be drawn without 
validation of the entire size range of a species. Since age estimates have not been properly validated for most elasmobranch species, future research needs to focus on first validating and then examining a species for the possibility of compensatory changes in age and growth parameters.

Acknowledgments We would like to thank the commercial and recreational fishermen who allowed us to sample their catches and all the scientists and observers, past and present, who obtained samples. We would also like to acknowledge the support of the Apex Predators Program staff. Jason Romine was very kind to spend time regenerating data to improve our age at maturity estimates. Allen Andrews and Simon Thorrold were excellent sounding boards for the bomb carbon analyses. In particular, we would like to thank Rich McBride; without his assistance we would not have obtained the initial funding for the bomb carbon work. He also provided valuable comments to our draft. This research was done consistent with applicable law.

\section{References}

Akaike H (1973) Information theory and the extension of the maximum likelihood principle. In: Petrov BN, Csaki F (eds) International Symposium on Information Theory. Academiai Kaido, Budapest, pp 267-281

Andrews AH, Natanson LJ, Kerr LA, Burgess GH, Cailliet GM (2011) Bomb radiocarbon and tag-recapture dating of sandbar shark (Carcharhinus plumbeus). Fish Bull 109:454-465

Ardizzone D, Cailliet GM, Natanson LJ, Andrews AH, Kerr LA, Brown TA (2006) Application of bomb radiocarbon chronologies to shortfin mako (Isurus oxyrinchus) age validation. Environ Biol Fish 25:355-366

Baty F, Delignette-Muller ML (2011) nlstools: tools for nonlinear regression diagnostics. $\mathrm{R}$ package version 0.0-11

Beamish RJ, McFarlane GA (1983) The forgotten requirement for age validation in fisheries biology. Trans Am Fish Soc 112(6):735-743

Benavides MT, Horn RL, Feldheim KA, Shivji MS, Clarke SC, Wintner S, Natanson L, Braccini M, Boomer JJ, Gulak SJB, Chapman D (2011) Global phylogeny of the dusky shark Carcharhinus obscurus: implications for fisheries management and monitoring in the shark fin trade. Endanger Species Res $14: 13-22$

Bowker AH (1948) A test for symmetry in contingency tables. J Am Stat Assoc 43:572-574

Burnham KP, Anderson DR (2002) Model selection and multimodel inference: a practical information-theoretic approach, 2nd edn. Springer, New York

Cailliet GM, Andrews AH (2008) Age-validated longevity of fishes: its importance for sustainable fisheries. In: Tsukamoto K, Kawamura T, Takeuchi T, Beard Jr TD, Kaiser MJ (eds) Fisheries for global welfare and environment. 5th World Fisheries Congress 2008, p 103

Cailliet GM, Yudin KG, Tanaka S, Taniuchi T (1990) Growth characteristics of two populations of Mustelus manazo from Japan based on cross-reading vertebral bands. In: Pratt Jr. HL, Gruber SH, Taniuchi T (eds) Elasmobranchs as living resources: advances in biology, ecology, systematics and the status of the fisheries. NOAA Technical Report NFMS 90, pp 167-176

Campana SE, Annand MC, McMillan JI (1995) Graphical and statistical methods for determining the consistency of age determinations. Trans Am Fish Soc 124:131-138

Campana SE, Natanson LJ, Myklvoll S (2002) Bomb dating and age determination of large pelagic sharks. Can J Fish Aquat Sci 59:450-455

Campana SE, Jones C, McFarlane GA, Myklevoll S (2006) Bomb dating and age validation using the spines of spiny dogfish (Squalus acanthias). Environ Biol Fish 25:327336

Campana SE, Casselman JM, Jones CM (2008) Bomb radiocarbon chronologies in the Arctic, with implications for the age validation of lake trout (Salvelinus namaycush) and other Arctic species. Can J Fish Aquat Sci 65:733-743

Carlson JK, Baremore IE (2003) Changes in biological parameters of Atlantic sharpnose shark Rhizoprionodon terraenovae in the Gulf of Mexico: evidence for density-dependent growth and maturity? Mar Freshwat Res 54:227-234

Cassoff RM, Campana SE, Myklevoll S (2007) Changes in baseline growth and maturation parameters of Northwest Atlantic porbeagle, Lamna nasus, following heavy exploitation. Can J Fish Aquat Sci 64:19-29

Compagno LJV (1984) FAO species catalogue. Sharks of the world: an annotated and illustrated catalogue of shark species known to date. Part 2: carcharhiniformes. FAO Fish Synop 125. FAO, Rome 4, pp 251-655

Cortés E (2002) Incorporating uncertainty into demographic modeling: application to shark populations and their conservation. Conserv Biol 4:1048-1062

Cortés E (2007) Chondrichthyan demographic modeling: an essay on its use, abuse and future. Mar Freshwat Res 58:4-6

Cortés E, Brooks E, Apostolaki P, Brown CA (2006) Stock assessment of dusky shark in the U.S. Atlantic and Gulf of Mexico. National Marine Fisheries Service Panama City Laboratory Contribution 06-05 and Sustainable Fisheries Division Contribution SFD 2006-014

Druffel ERM (1989) Decade time scale variability of ventilation in the North Atlantic: high-precision measurements of bomb radiocarbon in banded corals. J Geophys Res 94(C3):32713285. doi:10.1029/JC094iC03p03271

Evans GT, Hoenig JM (1998) Testing and viewing symmetry in contingency tables, with application to readers of fish ages. Biometrics 54:620-629

Francis MP, Campana SE, Jones CM (2007) Age under-estimation in New Zealand porbeagle sharks (Lamna nasus): is there an upper limit to ages that can be determined from shark vertebrae? Mar Freshw Res 58:10-23

Gedamke T, DuPaul WD, Musick JA (2005) Observations on the life history of the barndoor skate, Dipturus laevis, on Georges Bank (western North Atlantic). J Northwest Atl Fish Sci 35:67-78

Haddon M (2001) Modeling and quantitative methods in fisheries. Chapman \& Hall/CRC Press, Boca Raton

Harry AV, Tobin AJ, Simpfendorfer CA (2013) Age, growth and reproductive biology of the spot-tail shark Carcharhinus sorrah, and the Australian blacktip shark, C. tilstoni, from the Great Barrier Reef World Heritage Area, north-eastern Australia. Mar Freshw Res 64(4):277-293 
Hoenig JM, Morgan MJ, Brown CA (1995) Analyzing differences between two age determination methods by tests of symmetry. Can J Fish Aquat Sci 52:364-368

James KC, Ebert DA, Natanson, LJ, Cailliet GM (2013) Age and growth characteristics of the Starry Skate, Raja stellulata, with a description of life history and habitat trends of the central California, U.S.A., skate assemblage. Environ Biol Fish

Kalish JM, Johnston J (2001) Determination of school shark age based on analysis of radiocarbon in vertebral collagen. In: Kalish JM (ed) Use of the bomb radiocarbon chronometer to validate fish age. Final Report, FDRC Project 93/109. Fisheries Research and Development Corporation, Canberra, Australia, pp 116-122

Kerr LA, Andrews AH, Cailliet GM, Brown TA, Coale KH (2006) Investigations of $\Delta^{14} \mathrm{C}, \delta^{13} \mathrm{C}$, and $\delta^{15} \mathrm{~N}$ in vertebrae of white shark (Carcharodon carcharias) from the eastern North Pacific Ocean. Environ Biol Fish 77:337-353

Kneebone J, Natanson LJ, Andrews AH, Howell WH (2008) Using bomb radiocarbon analyses to validate age and growth estimates for the tiger shark, Galeocerdo cuvier, in the western North Atlantic. Mar Biol 154:423-434

Kohler NE, Casey JG, Turner PA (1995) Length-weight relationships for 13 species of sharks from the western North Atlantic. Fish Bull 93(2):412-418

McNemar Q (1947) Note on the sampling error of the difference between correlated proportions or percentages. Psychometrika 12:153-157

McPhie RP, Campana SE (2009) Bomb dating and age determination of skates (family Rajidae) off the Eastern coast of Canada. ICES J Mar Sci 66:546-560

Natanson LJ (1993) Effect of temperature on band deposition in the little skate, Raja erinacea. Copeia 1993(1):199-206

Natanson LJ, Cailliet GM (1990) Vertebral growth zone deposition in Pacific angel sharks. Copeia 1990:1133-1145

Natanson LJ, Casey JG, Kohler NE (1995) Age and growth of the dusky shark, Carcharhinus obscurus, in the western North Atlantic. Fish Bull 93:116-126

Natanson LJ, Mello JJ, Campana SE (2002) Validated age and growth of the porbeagle shark (Lamna nasus) in the western North Atlantic Ocean. Fish Bull 100(2):266-278

Natanson LJ, Wintner SP, Johansson F, Piercy A, Campbell P, De Maddalena A, Gulak SJB, Human B, Cigala Fulgosi F, Ebert DA, Fong JD, Hemida F, Mollen FH, Vanni S, Burgess GH, Compagno LJV, Wedderburn-Maxwell A (2008) Preliminary investigation of vertebral band pairs in the basking shark Cetorhinus maximus (Gunnerus). MEPS 361:267-278

NMFS (1999) Final fishery management plan for Atlantic tunas, swordfish, and sharks. Volumes I and II. National Marine Fisheries Service, Silver Spring

NMFS (2003) Final amendment 1 to the fishery management plan for Atlantic tunas, swordfish, and sharks. National Marine Fisheries Service, Silver Spring

NMFS (2011) SEDAR 21 stock assessment report: sandbar, dusky, and blacknose sharks. SEDAR, 4055 Faber Place Drive, Suite 201, North Charleston, SC 29405. 415 pp
Passerotti MS, Carlson JK, Piercy AN, Campana SE (2010) Age validation of great hammerhead shark (Sphyrna mokarran), determined by bomb radiocarbon analysis. Fish Bull 108:346-351

R Core Team (2012) R: a language and environment for statistical computing. R Foundation for Statistical Computing, Vienna

Ricker WE (1975) Computation and interpretation of biological statistics of fish populations. Bull Fish Res Board Can 23:519-529

Ricker WE (1979) Growth rates and models. In: Hoar WS, Randall DJ, Brett JR (eds) Fish physiology, vol. VIII, bioenergetics and growth. Academic Press, pp 677-743

Romine JG, Musick JA, Burgess GH (2009) Demographic analyses of the dusky shark, Carcharhinus obscurus, in the Northwest Atlantic incorporating hooking mortality estimates and revised reproductive parameters. Environ Biol Fish 84:277-289

Rose KA, Cowen JH Jr, Winemiller KO, Myers RA, Hilborn R (2001) Compersatory density dependence in fish populations: importance, controversy, understanding and prognosis. Fish Fish 2:293-327

Sæther BE, Lande R, Engen S, Weimerskirch H, Lillegard M, Altwegg R, Becker PH, Bregnballe T, Brommer JE, McCleery RH, Merilä J, Nyholm E, Rendell W, Robertson RR, Tryjanowski P, Visser ME (2005) Generation time and temporal scaling of bird population dynamics. Nature 426:99-102

Schnute J (1981) A versatile growth model with statistically stable parameters. Can J Fish Aquat Sci 38:1128-1140

Sminkey TR, Musick JA (1995) Age and growth of the sandbar shark, Carcharhinus plumbeus, before and after population depletion. Copeia 1995:871-883

Springer S (1960) Natural history of the sandbar shark, Eulamnia milberti. Fish Bull 61:1-38

Stuiver M, Polach HA (1977) Discussion: reporting of ${ }^{14} \mathrm{C}$ data. Radiocarbon 19:355-363

Taylor IG, Gallucci VF (2009) Unconfounding the effects of climate and density dependence using 60 years of data on spiny dogfish (Squalus acanthias). Can J Fish Aquat Sci 66:351-366

Tillet BJ, Meekan MG, Field IC, Hua Q, Bradshaw CJA (2011) Similar life history traits in bull (Carcharhinus leucas) and pig-eye (C. amboinensis) sharks. Mar Freshwat Res 62:850860

Tuross N, Fogel ML, Hare PE (1988) Variability in the preservation of the isotopic composition of collagen from fossil bone. Geochim Cosmochim Acta 52:929-935

von Bertalanffy L (1938) A quantitative theory of organic growth (inquiries on growth laws II). Hum Biol 10:181-213

Walker TI (1998) Can shark resources be harvested sustainably? A question revisited with a review of shark fisheries. Mar Freshwat Res 49:553-572

Zuur AF, Ieno EN, Walker NJ, Saveliev AA, Smith GM (2009) Mixed effects model and extension in ecology with $\mathrm{R}$. Springer, New York 